\title{
Development of an Android-Based Application as an Information System for Sports Venues and Sport Community
}

\author{
Glady Sukma Perdana, Widiyanto*, Ilham \\ Faculty of Sport Science, Yogyakarta State University, Indonesia
}

Received July 21, 2021; Revised September 2, 2021; Accepted September 26, 2021

\section{Cite This Paper in the following Citation Styles}

(a): [1] Glady Sukma Perdana, Widiyanto, Ilham, "Development of an Android-Based Application as an Information System for Sports Venues and Sport Community, "International Journal of Human Movement and Sports Sciences, Vol. 9 , No. 6, pp. 1131 - 1139, 2021. DOI: 10.13189/saj.2021.090608.

(b): Glady Sukma Perdana, Widiyanto, Ilham (2021). Development of an Android-Based Application as an Information System for Sports Venues and Sport Community. International Journal of Human Movement and Sports Sciences, 9(6), 1131 - 1139. DOI: 10.13189/saj.2021.090608.

Copyright $\odot 2021$ by authors, all rights reserved. Authors agree that this article remains permanently open access under the terms of the Creative Commons Attribution License 4.0 International License

\begin{abstract}
The application developed is android-based AYOOLAHRAGA ${ }^{1}$, which is an information system for sports venues and sports communities for smartphone users. This development of such application has the main purpose to help users to find out some information readily and quickly about physical activities fields available in Yogyakarta and the nearest places. The information developed in the AYOOLAHRAGA application can be accessed by anyone having a smartphone especially those residing in Yogyakarta city (DIY). This research is a product development study, popularly known as Research and development (R\&D) research. Whilst collecting data, three types of instruments were employed, namely a questionnaire for expert media validators, along with two different tests administered in two terms based on the sample size involved. The small-scale test used a sample of 50 respondents whereas the large-scale sample consists of 100 respondents. The data were analysed using quantitative and qualitative approaches. After addressing all data, it was revealed that the results of the material expert test obtained a percentage of $98.82 \%$, felt in strongly agree category of application acceptance while the media expert test obtained a percentage of $97.21 \%$ likewise. The results of the small
\end{abstract}

\footnotetext{
${ }^{1}$ Downloading information AYOOLAHRAGA is available in this link below:

https://play.google.com/store/apps/details?id=com.digitcreativestudio.ay oolahragaid
}

and large-scale testing showed that most respondents stated that the development of the present application for sports lovers' benefits is good and needed so far. Therefore, it can be concluded that an android-based sports venues and sports community information system is useful and feasible to use.

Keywords Information System, Sports Venue, Sports Community, Android-Based Development

\section{Introduction}

By not being a panacea for all human problems rather than a breakthrough in various facets of life, the presence of technology has so far become an essential part of human development. Thus, in these modern times, the telephone for communication, the Global Positioning system popularly known as GPS to guide travelers and drivers, the internet to search for information, and many others are the main aspects marked by technology in these modern times [1], [2]. Being a lattice of technology, information technology is something that is also evolving at a rapid pace based on the needs and the sake of the users, which is smartphone/android phones owned by many worldwide so far. On the side of Indonesia, smartphones user keeps increasing as the time goes especially during this 
unprecedented disease [3]. Regardless of the throughputs where the smartphone is intervened/intervening especially through information systems, the community of physical activity or sports lovers indeed can also benefit from that digital system while seeking sports venues, recognized physical activity fields, or inviting people to participate in such healthy activities.

Acknowledged to have developed into a science that can boost a country's economy, the activities of the sports industry, tourism, education, health, and others sports have the benefits of fitness recognized as an important component of a healthy lifestyle [4], [5]. In the health sector, sports activities are known to reduce depression, stress, and anxiety, along with increase self-confidence, energy levels, sleep quality, and the ability to concentrate [6], [7]. Moreover, improved health through physical activity can prevent non-communicable diseases such as cancer, stroke, kidney disease, diabetes, and hypertension [8]. In a broad sense, all activities that can occur spontaneously like leisure, work, transport or organized activities are broadly named physical activities [4]. However, the term physical activity can have a compound meaning composed of physical exercise and physical training where physical exercise aims primarily at improving health and physical capacity [9]whereas physical training is done for increasing the individual's maximum physical capacity and performance [4]. On contrary, physical inactivity is described as the absence of body movement, when energy consumption approximates resting levels. People who do not do physical activity as recommended are considered physically inactive or sedentary individuals [10], [11]. From here, one may wonder how information systems for sports venues and sports communities can restrict some people to reach such benefits especially in Yogyakarta, Indonesia. Simply, Indonesia is known as a country with a long tradition in sports. Badminton game is ranked to be the national sport of Indonesia, but Indonesians also still enjoy football, basketball, cycling, boxing, and many other games. Sepak takraw and Pencak Silat, a martial art native is also classified among other interesting traditional sports find in Indonesia. When talking of sports venues, we simply mean the recognized locations of these public fields where physical activities are freely performed. However, sports community or community sports clubs refers to all social physical activity that fosters health promotion through involving in physical activity in the community. It is asserted by [12] as the process of enabling people to increase control over and to improve their health through physical activity [13], [14].

According to some experts like [15], [16] the Indonesian people are still less aware of the importance of a healthy lifestyle. The lack of public interest and appreciation for sports are some of the reasons reported by many. The National Socioeconomic Survey results showed that the participation of the population aged 10 years and over in doing sports had decreased over time especially in the years 2000 and 2009 with $25.4 \%$ and $21.8 \%$ respectively. However, when comparing the rural and urban areas in terms of sports participation, the urban is much better due to the disparity in facilities and types of sports that literally developed in cities than in villages. To embark and foster sports participation chiefly in the community, and adequate information system is deemed to bridge such a gap by helping people to avoid inactivity problems. Active living is a way of life that incorporates physical activity into daily routines [17]. As a vital investment, physical activity fans face challenges in the built environment to find open areas and free fields. For example, in Europe overall, car transport has highly increased and travel by bicycle and on foot has significantly declined [18]. Growing dependence on cars especially in urban sprawl, including Yogyakarta city is both a cause and result of suburbanization and subsequently the lack of free areas for physical activities. Although limited room for green spaces is still a big challenge in cities, lack of a sports information system to obtain information on sports venues and communities is also a pertinent question. Particularly in the cities, based on people's needs, throughout the cities, the availability of these free spaces for physical activity exists and is abundant even though they are in the business frame where accessing them, paying is a mandatory requirement.

Based on the observations and interviews on the field, most of the participants we encounter and interviewed expressing that the lack of information systems that make it easier to find these free spaces henceforth sports venues is prevalent. For some, it is difficult to find sports venues and sports communities even though sometimes they are closer and in line with their wishes. This research was done in the form of a program that can be used to find information about sports venues and sports communities in DIY, so that the community, especially newcomers can easily get sports information and then increase sports participation. However, the research question was set up as follows. Is the development of the AYOOLAHRAGA application as an information system for sports venues and sports communities easy for smartphone users to use and feasible for the community and students indeed?

\section{Research Method}

\subsection{Information Gathering}

It was executed into two distinctive moments namely straight observation on the field, and Play store survey. The results of the preliminary study were performed through interviews, questionnaire surveys. Overall, the information obtained at such stage leads us to draw the following conclusions; less known and lack of information media for sports venues and sports communities. Google map was the only one information system used by more users while 
seeking information about sports venues since some lack valid place information. As far as the play store survey is concerned, our exploration results of the play store survey obtained several sports applications that are mostly workout/fitness exercises with search keywords, namely sports venues and sports communities. However, to our best understanding, we have not found an application that is specifically a search application for sports venues and sports communities.



Figure 1. The interface figure depicted on survey play store with keywords sports venues and community 


\subsection{R \& D Research Design}

This study used the Research and Development method, which is a research method used to produce certain products by testing its feasibility and effectiveness from the beneficiaries' point of view [19]. The research design includes 1) potentials and problems; (the information in finding the desired sports venues and sports communities is not appropriate even though there are many sports venues and sports communities around the DIY province), 2) information gathering; (so far there has been no android application offering information on sports venues and sports communities, which is operated using a smartphone with an internet connection), 3) product design; (the android application that has been made has a simple display/interface with a menu that is easier to understand by users and making it easier to access the "Ayoolahraga" android application. Designing the flow of information systems for sports venues and sports communities was endorsed by the Entity-Relationship Diagram (ERD) modeling made through the CorelDraw application, which is a model for compiling databases in the system. It was employed to help to depict and describe data that has a relationship with the database to be designed. It can help to visualize how data is interconnected and is useful for constructing relational databases. 4) design validation; (the final products from the research has been validated by experts or experienced experts to assess the new products that have been designed, in order to find out its weaknesses and strengths), 5) design revision; (since the product weakness is known, improvements were made to minimize product shortcomings), 6) small group test; (small group trials were conducted with students accessing android and looking for information on sports venues available on android being developed, and later on small group test revision, 7) large group test; (the trial process was observed by android application users totaling 300 subjects, from four districts in Yogyakarta region, then afterward large group test revision was performed), 9) final product; (based on its feasibility and suitability value, this product developed will support infrastructure and information on sports venues and communities to be more efficient and easy to locate). Sampling in this development research is based on random sampling and was conducted in Yogyakarta as the research site. On September 1, 2020, small-scale testing subjects were executed consisting of 50 respondents along with a questionnaire. On the other hand, the large-scale testing subjects were 100 respondents consisting of the community and DIY students.

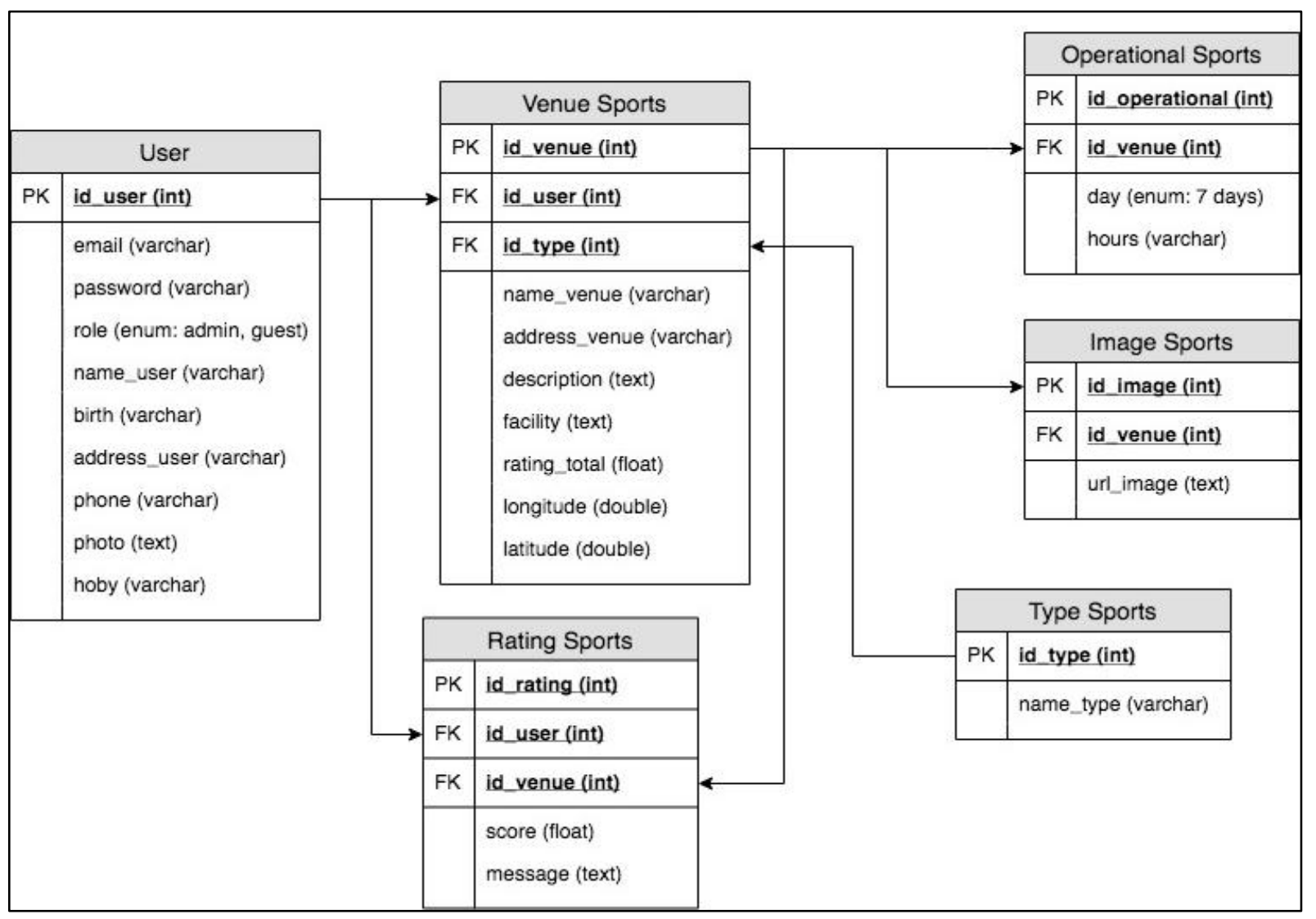

Figure 2. Entity Relationship Diagram (ERD) modeling 


\subsection{Data Analysis Technique}

For data analysis, qualitative and quantitative descriptive analyses were used. The quantitative descriptive analysis was carried out to analyze the following data: 1) value scale data from the assessment results, 2) the results of the assessment of application products and manual users, 3 ) the results of small-scale trials, and (4) large-scale trial data. The Likert scare was used by both experts and respondents while validating the new product, which is an android application. The scale employed has five types of values, namely "strongly agree" worth 5 (five), "agree" worth 4 (four), "neutral" worth 3 (three), "not agree/disagree" worth 2 (two) and for the answer "strongly disagree" worth 1 (one). Converting score obtained referred to benchmark valuation standards or standard penilaian patokan (PAP) in the Javanese language.

According to [20], [21], [22], the standard benchmark valuation used is summarized as follows:

Table 1. Summary of Standard Benchmark Valuation Endorsed

\begin{tabular}{|c|c|c|}
\hline Score value & Category & Description \\
\hline $81 \%-100 \%$ & A & Strongly agree \\
\hline $61 \%-80 \%$ & B & Agree \\
\hline $41 \%-60 \%$ & C & Satisfaction \\
\hline $21 \%-40 \%$ & D & Not agree/disagree \\
\hline $0 \%-20 \%$ & E & Strongly disagree \\
\hline
\end{tabular}

\section{Results}

The final product of this current study is an android application for the information system of sports venues and sports communities in Yogyakarta city. In Indonesia. The gist of this development was to intervene and contribute to physical activity in order to become more efficient and easier to use. Through various steps of validations before being used, the final product is presented as follow:

Front interface loading: when you first open the application, a loading page will appear which is awaiting page when the application prepares its data. You can see a blue background and a sports application logo in the middle of figure 3 .

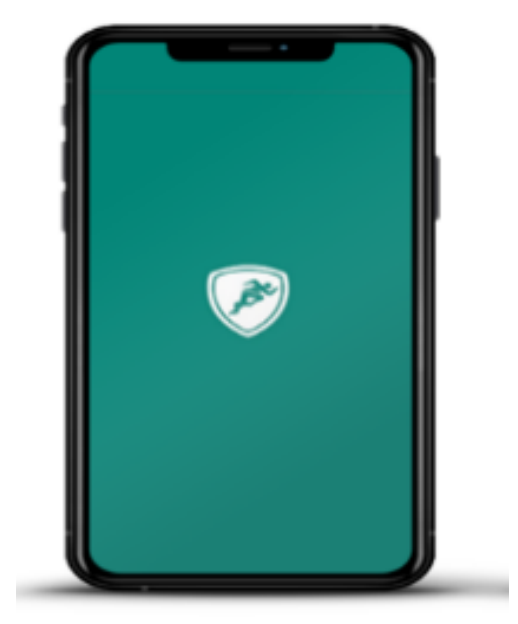

Figure 3. The final product interface loading

The interface of the final product for sports venue: the category page displays sports venues according to the category.

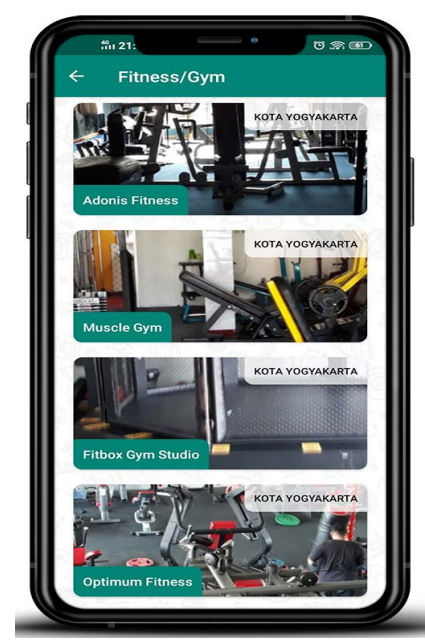

Figure 4. Interface of the final product for sports venues

The depiction of interface page for sports community: The community detail page displays some community information such as pictures/photos, community name, community description, training schedule, and community contact. 


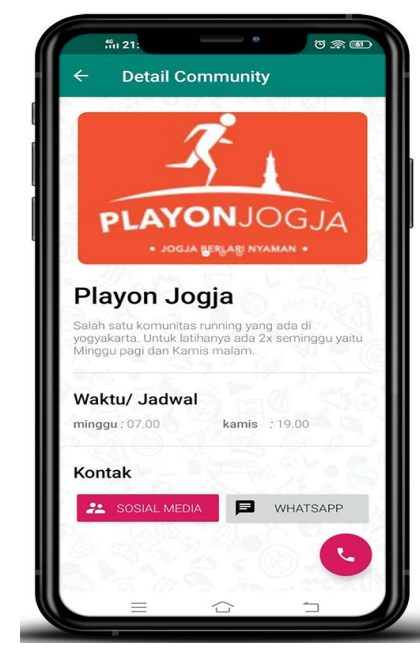

Figure 5. Interface spot of the final product for the sports community

Although the interfaces showcased above are designed either for sports venues or sports communities, this developed application has also other interfaces designed for the same purpose. Some of them are, 1) interface favorite page; (that is a page where the user saves his favorite sports place so that when you open the application again, you don't have to look for another place, just open the favorite page with the heart logo; 2 ) user page; (that is a page that contains user information who has registered in the AYOSPORTS APPLICATION. There is information on name, phone number, email, address, hobbies, and exit button; 3) setting/configuration page (it is a page for managing applications, including language settings. Moreover, on this page, there is a tutorial for users who are still confused about using the application) and so forth.

\subsection{Results of the Material Expert Assessment}

Table 2. Result of Material Expert Assessment

\begin{tabular}{|c|c|c|c|}
\hline Aspect & Value obtained & Max. value & \% \\
\hline Application & 50 & 50 & 100 \\
\hline Guidebook & 83 & 85 & 97.64 \\
\hline \multicolumn{3}{|c|}{ Average } & 98.82 \\
\hline
\end{tabular}

The results depicted above of the material expert validation showed that the percentage in the android aspect was $100 \%$, while the percentage in the application manual aspect was $97.64 \%$. With these results, an average percentage of $98.82 \%$ is obtained. With these results, it can be interpreted that that the Android-based Sports Place and Sports Community Information System is very useful and good to use.

\subsection{Results of the Media Expert's Assessment}

After being assessed by material and media experts, the scores obtained are presented in the table 3. As we can see, the product was tested on small groups with the minimum criterion for a "very poor" rating. With the scores obtained from material and media experts, it can be concluded that the development of this new Android-based application for smartphone users was ready to be tested. Furthermore, small-size testing was carried out using 50 respondents consisting of students and the community in DIY. The results of the 1st media expert validation obtained the percentage of the android aspect is $96.84 \%$, and the percentage of the application manual aspect is $97.64 \%$. The results of the second media expert validation obtained the percentage of the android aspect is $97.89 \%$, and the percentage of the application manual aspect is $96.47 \%$. Based on these results, an average percentage of $97.21 \%$ is obtained. With these results, it can be concluded that the Android-based development was beneficial and good to be implemented.

Table 3. Results of the Media Expert Assessment

\begin{tabular}{|c|c|c|c|c|}
\hline Expert & Aspect & $\begin{array}{c}\text { Value } \\
\text { obtained }\end{array}$ & $\begin{array}{l}\text { Max. } \\
\text { value }\end{array}$ & $\%$ \\
\hline \multirow{2}{*}{$\begin{array}{l}\text { Media } \\
\text { Expert } 1\end{array}$} & Application & 92 & 95 & 96.84 \\
\hline & Guidebook & 83 & 85 & 97.64 \\
\hline \multirow{2}{*}{$\begin{array}{l}\text { Media } \\
\text { Expert } 2\end{array}$} & Application & 93 & 95 & 97.89 \\
\hline & Guidebook & 82 & 85 & 96.47 \\
\hline \multicolumn{4}{|c|}{ Average } & 97.21 \\
\hline
\end{tabular}

\subsection{Results of Small-Scale Testing}

Table 4. Results of the small-scale testing group

\begin{tabular}{|c|c|c|c|c|c|}
\hline \multirow{2}{*}{ Range Score } & \multirow{2}{*}{ verdict } & \multicolumn{2}{|c|}{ Application } & \multicolumn{2}{c|}{ Guidebook } \\
\cline { 3 - 6 } & & amount & $\%$ & amount & $\%$ \\
\hline $81 \%$ to $100 \%$ & Very good & 0 & 0 & 7 & 14 \\
\hline $61 \%$ to $80 \%$ & Good & 50 & 100 & 43 & 86 \\
\hline $41 \%$ to $60 \%$ & Enough & 0 & 0 & 0 & 0 \\
\hline $21 \%$ to $40 \%$ & Fair & 0 & 0 & 0 & 0 \\
\hline $0 \%$ to $20 \%$ & Poor & 0 & 0 & 0 & 0 \\
\hline
\end{tabular}

Based on the results of small-scale testing on the development of the Android-based application for smartphone users, it is shown that most of the respondents are in the Android aspect along with the guidebook. Both these aspects were rated good, respectively. Although the results of the small testing assessment showed a good rating, inputs from respondents were still needed. Therefore, the application product of this sports venue information system was immediately revised and then large-scale testing was carried out on 100 respondents consisting of students and the DIY community.

\subsection{Large-Scale Testing Results}

The application product test was carried out by operating the android application with a smartphone. This is intended to determine the feasibility of an android application 
developed for information on sports venues and communities. The large-scale testing process was observed by android application users. By using 100 subjects during the testing process, the results of small-scale testing revealed that most of the respondents on the android aspect rated it good in tandem, in the assessment aspect of the guidebook a substantial portion of respondents rated it good as well. The final product of this research is the development of an android-based application for sports venues and sports communities for smartphone users. As depicted in table 5, while testing the product with large-scale groups, the results were impressive when the highest verdict found was well represented by $63 \%$ for the new application and 55\% for the guidebook. Based on these results, respondents in large-scale trials stated that the Android-based Sports Places and Sports Community Information System was declared good for use as a media for Sports Places and Sports Community Information.

Table 5. Large Scale Results

\begin{tabular}{|c|c|c|c|c|c|}
\hline \multirow{2}{*}{ Range Score } & \multirow{2}{*}{ Verdict } & \multicolumn{2}{|c|}{ Application } & \multicolumn{2}{c|}{ Guidebook } \\
\cline { 3 - 6 } & & Amount & $\%$ & Amount & $\%$ \\
\hline $81 \%$ to $100 \%$ & Very good & 27 & 27 & 45 & 45 \\
\hline $61 \%$ to $80 \%$ & Good & 63 & 63 & 55 & 55 \\
\hline $41 \%$ to $60 \%$ & Enough & 0 & 0 & 0 & 0 \\
\hline $21 \%$ to $40 \%$ & Fair & 0 & 0 & 0 & 0 \\
\hline $0 \%$ to $20 \%$ & Poor & 0 & 0 & 0 & 0 \\
\hline
\end{tabular}

\section{Discussion}

The research and development phases of the android-based application developed to help in finding out sports venue and community in Yogyakarta city begins with a requirement analysis for discovering the reason why the number of people who involve in physical activity keeps decreasing. The results of requirement analysis were helped by an interview conducted whose final results indicated that there are some difficulties regarding the information system that can help them to track easily some physical fields spots [23]. This issue is not only experienced by students or the young generation but rather by a big portion of the community in the same area [18]. Based on the literature and interview results, these difficulties should be overcome because of the benefits of physical activities and for the sake of people. One effort that has been done was by developing an android-based application that incorporated an information system to ease to locate these places. The effectiveness and feasibility of this new product consists of three levels of testing, such as questionnaire, large and small scare testing. The application format developed is an application format that can be used on Android-based smartphones. Android-based application product was further validated by experts and respondents.
The information system is defined as a system within an organization consisting of people, facilities, technology, media, procedures, and controls aim at getting the intended combination path [24], because in this digital era, human life is inseparable from communication and digital tools that can provide practical communication and owned by almost every human being. These good and fast information systems can help people access the information they want, one of which is information on sports [25] \& [26]. Sport venue managers, sports communities can benefit from this information system developed to introduce and invite people to participate in physical activity and exercise [27]. As far as the venue for the community is concerned, we acknowledge that people's interest in sports in the world of technology has grown so rapidly recently [28], [29], including the Special Region of Yogyakarta, which has wide and strategic areas to provide an effective and efficient information system for the community for such purpose.

Based on the results of the material expert test, the average percentage was $98.82 \%$, while the results of the media expert test showed an average percentage of $97.21 \%$. The results of the expert test revealed that the development of the Android-based application as an information system for sports venues and sports communities for the smartphone was good. Our results were corroborated with the one of [30] who developed a health application that helps people to keep their ideal body weight and to maintain it by having controlled food intake and exercises. The application developed in that way has indeed helped people to get and maintain their ideal body weight. The results of the testing on a small scale and a large scale showed that most respondents stated also that this new application was quite fine. The results, therefore, indicate that users provide convenience for the public in providing information related to information on sports venues and sports communities in DIY. This development will support infrastructure suggestions and information on sports venues and communities to be more efficient and easier to use.

\section{Conclusions}

Based on these results, it can be concluded that the development of the Android-based AYOOLAHRAGA application as an information system for sports venues and sports communities for smartphone users is declared good and feasible to use. For that reason, this application can help users to get some information about physical activities fields available around them quickly and effectively. Also, based on the health benefits of doing physical activity, the presence of this application will contribute to reducing some diseases as well as improving the well-being of people. At the end of the day, hopefully, this mobile app developed will contribute to the society where people and 
particularly young people do not spend their precious time in gadget or mobile phone only so far. This mobile app will also form new friendships through similar favorite hobbies, particularly in physical activity sports. To make this mobile app better, inviting businesses to advertise their product mainly sports items and goods will be a precious opportunity to raise the income for the developers.

\section{REFERENCES}

[1] R. Bajaj, S. L. Ranaweera, and D. P. Agrawal, "GPS: location-tracking technology," Computer (Long. Beach. Calif)., vol. 35, no. 3, pp. 92-94, 2002, doi: $10.1109 / 2.993780$.

[2] A. C. O'Connor et al., "Economic Benefits of the Global Positioning System (GPS),” no. 0215471, p. 306, 2019.

[3] J. H. Park and M. Park, "Smartphone use patterns and problematic smartphone use among preschool children," PLoS One, vol. 16, no. 3 March, pp. 1-12, 2021, doi: 10.1371/journal.pone.0244276.

[4] C. Malm, J. Jakobsson, and A. Isaksson, "Physical Activity and Sports-Real Health Benefits: A Review with Insight into the Public Health of Sweden," Sports, vol. 7, no. 5, p. 127, 2019, doi: 10.3390/sports7050127.

[5] J. A. Phillips and D. R. Young, "Past-year sports participation, current physical activity, and fitness in urban adolescent girls," J. Phys. Act. Heal., vol. 6, no. 1, pp. 105111, 2009, doi: 10.1123/jpah.6.1.105.

[6] A. K. Bowe, M. Owens, M. B. Codd, B. A. Lawlor, and R. W. Glynn, "Physical activity and mental health in an Irish population," Ir. J. Med. Sci., vol. 188, no. 2, pp. 625-631, 2019, doi: 10.1007/s11845-018-1863-5.

[7] I. Ilham and D. Dimyati, "The Effect of Visualization, Relaxation, and Self-efficacy on the Performance of Men Speed World Record Athletes Category," Int. J. Hum. Mov. Sport. Sci., vol. 9, no. 1, pp. 48-55, Jan. 2021, DOI: 10.13189/saj.2021.090107.

[8] O. Landrove-Rodríguez et al., "Non-communicable diseases: Risk factors and actions for their prevention and control in Cuba," Rev. Panam. Salud Publica/Pan Am. J. Public Heal., vol. 42, pp. 1-8, 2018, doi: 10.26633/RPSP.2018.23.

[9] U. T. Brasov and F. M. Clemente, "Exercise and sports in men : from health to sports performance," no. June, 2021.

[10] G. N. Healy et al., "Objectively measured sedentary time, physical activity, and metabolic risk the Australian Diabetes, Obesity and Lifestyle Study (AusDiab)," Diabetes Care, vol. 31, no. 2, pp. 369-371, 2008, doi: 10.2337/dc07-1795.

[11] A. A. Thorp et al., "Prolonged sedentary time and physical activity in workplace and non-work contexts: A cross-sectional study of office, customer service and call centre employees," Int. J. Behav. Nutr. Phys. Act., vol. 9, pp. 1-9, 2012, doi: 10.1186/1479-5868-9-128.

[12] J. Robertson, R. Eime, and H. Westerbeek, "Community sports clubs: are they only about playing sport, or do they have broader health promotion and social responsibilities?," Ann. Leis. Res., vol. 22, no. 2, pp. 215-232, 2019, doi: 10.1080/11745398.2018.1430598.

[13] Who, "Examples from the WHO Small Countries Initiative," 2020.

[14] I. Kickbusch and D. Gleicher, "Governance for Health in The 21st century," Who, pp. 1-106, 2012.

[15] A. P. Study, "Indonesian Version of the Healthy Lifestyle Beliefs Scale for College Student: Journal of Physical Education, Sport," no. February, 2021, doi: 10.15294/acti ve.v10i1.44988.

[16] "Indonesian youth."

[17] T. Hormenu and E. W. Ansah, "Developing and Promoting Active Lifestyles for Healthy Living and National Development," Ghana J. Heal. Phys. Educ. Recreat. Sport Danc., vol. 11, no. 1, pp. 60-75, 2018.

[18] FACTS Promoting physical activity and active living in urban.

[19] S. Gustiani, "Research and Development ( R \& D ) Method as a Model Design in Educational Research and Its Alternatives," Holistics J., vol. 11, no. 2, pp. 12-22, 2019.

[20] IVSC, "International Valuation Standards (IVS)," Int. Valuat. Stand. Counc., no. January, 2020.

[21] D. Sutejo, H. Kusmanto, W. Warjio, and A. A. Lubis, "Implementasi Undang-Undang Tentang Administrasi Kependudukan Di Dinas Kependudukan dan Pencatatan Sipil Kabupaten Aceh Timur," Strukt. J. Ilm. Magister Adm. Publik, vol. 2, no. 2, pp. 162-167, 2020, doi: 10.31289/strukturasi.v2i2.56.

[22] Sugiyono, "Sugiyono Metode Penelitian Kuantitatif Kualitatif," Metod. Penelit. Kuantitatif Kualitatif, p. 6, 2009.

[23] B. R. Kurniawan, M. I. Shodiqin, D. E. Saputri, M. N. Kholifah, and Y. Affriyenni, "Development of android-based assessment to improve student's concept acquisition on vector topics," AIP Conf. Proc., vol. 2215, no. August, 2020, doi: 10.1063/5.0000572.

[24] K. C. Laudon and J. P. Laudon, Management Information Systems Managing The digital Firm Thirteen Edition Global Edition (SIB). 2014.

[25] "Participating in sport and physical activity helps Australians to enjoy healthier, Sport in Australia," no. July, pp. 1-6, 2021.

[26] H. Can, M. Lu, and L. Gan, "The research on application of information technology in sports stadiums," Phys. Procedia, vol. 22, pp. 604-609, 2011, doi: 10.1016/j.phpro.2011.11.0 93.

[27] J. Ndayisenga and Tomoliyus, "Effect of service quality and rates on satisfaction and loyalty of customer behavior at fitness," Int. J. Hum. Mov. Sport. Sci., vol. 7, no. 2, pp. 2532, 2019, DOI: 10.13189/saj.2019.070202.

[28] UNCTAD/TIR, And innovation 2021. 2021.

[29] S. Waite, "The Fourth Industrial Revolution and the Future 
of Work - RevUnit,” Revunit, no. 02, 2018.

[30] A. Aulia, F. Tanzil, I. K. Wairooy, L. K. Gunawan, A. Cunwinata, and Albert, "A development of android-based mobile application for getting ideal weight," Telkomnika

Telecommunication Comput. Electron. Control., vol. 16, no. 3, pp. 1289-1294, 2018, doi: 10.12928/TELKOMNIK A.v16i3.8342. 